\title{
DYNAMIC FINANCIAL ANALYSIS WITH DEPENDENCE BETWEEN MOTOR OWN DAMAGE INSURANCE AND COMPULSORY MOTOR INSURANCE USING COPULAS - THE CASE OF TURKEY
}

\author{
Betül Zehra KARAGÜL ${ }^{1, ~ *}$, Murat BÜYÜKYAZICI ${ }^{1}$ \\ ${ }^{1}$ Department of Actuarial Science, Faculty of Science, Hacettepe University, 06800, Ankara, Turkey
}

\begin{abstract}
Dynamic Financial Analysis (DFA) is used by insurance companies for an efficient asset liability management and profit optimization; to measure ruin probability and reduce various risks. In this paper, the influence of the dependence between compulsory motor insurance and motor own damage insurance, that are two really important lines of business for nonlife insurance, on the risk, return and performance in a nonlife insurer's DFA is investigated. The dependency is integrated to the DFA framework using copulas. In the application non-life insurance data of Turkey is used.
\end{abstract}

Keywords: Dynamic Financial Analysis, Dependency between lines of business in insurance, Copulas, Non-life insurance, Simulation

\section{INTRODUCTION}

Financial modeling has an important role for insurance companies to predict the future. Thereby they can do risk assessment, estimate their future/next term's profit, make performance evaluation. Nowadays, one of the most efficient and common used financial models is DFA.

DFA is used more often in non-life insurance because severity of claims and the time of occurrence in non-life insurance products are less certain than life insurance products.

For the first time, the Casualty Actuarial Society has built a DFA model for property-casualty insurers [1]. Since then, many articles have been published on DFA [2-5]. Each company can build a DFA model which includes the useful components for itself. In this study, a DFA model is used which contains the basic components that may be required and enough for a non-life insurance company. [6].

One of the most important components in DFA of a nonlife insurance company is claims.It is important for companies to examine the claims in terms of business lines. This situation makes this necessary to investigate the dependency between the business lines and to intagrate it into the financial analysis.

The purpose of this study is to analyze the effects of correlation between compulsory motor (CM) insurance and motor own damage (MOD) insurance which are the biggest shares of claims in Turkey's nonlife insurance claims data and have important effects on the insurer's asset liability management. The dependence structure is integrated into the DFA model with copula functions.

Theterm copula was first used in the work of Sklar [7]. Since then about insurance and analyzing of capital markets many studies have been done with copulas [8-13]

In this study both elliptical copulas (Student-t and Gaussian) and most popular Archimedian copulas (Gumbel, Clayton and Frank) are used.

*Corresponding Author: betul.zehra@hacettepe.edu.tr 
This paper is organized as follows: DFA methodology is introduced and DFA model framework which includes the basic components for a nonlife insurance company is presented in section 2. Section 3 "Copula Methodology", consists of some important families of copulas and their properties. In section 4, Turkey insurance data is used in the simulation study to analyze the effects of the dependency between MOD insurance and CM insurance on DFA. Section 5 concludes the study with the obtained results and certain suggestions for further research.

\section{DFA METHODOLOGY}

DFA is a financial modeling approach and helps the users about performance measurement, capital allocation, pricing decisions, product designing and valuation, analysis of major risks. DFA based on large-scale computer simulations. DFA is a useful tool for financial analysis of nonlife insurance companies. They should pay close attention to both assets and liabilities. Therefore they can integrate the interest rates, premium rates, the choice of investment tools and their proportion, the proportion of lines of business into the model dynamically.

There is not a unique methodology for DFA. Companies can construct different models that include necessary components for themselves. A general DFA process will follow these steps respectively; set goals and objectives, collect data, parameterize model, generate model runs, analyze output, test sensitivity and present findings [14].

The most important issue when you want to construct a DFA model is choosing the right components that must be in the model and integrate them into the model correctly.

Now we present the DFA model framework which is used in the application. In this paper we use a DFA model which contains the basic components for a non-life insurance company and created by Martin Eling and Denis Toplek [15]. We extend this framework with lines of business (compulsory motor 'CM' and motor own damage 'MOD') and make some modifications for premium level.

$E C_{T}$ is used as the equity capital of the insurance company at the end of time period $\mathrm{t}$ $(t \in 1, \ldots ., T)$ and $E_{t}$ the company's earnings in t. Therefore, the development of the equity capital overtime is as shown below;

$$
E C_{T}=E C_{t-1}+E_{t}
$$

To find the company's earning $\left(E_{t}\right)$ we add the investment result $\left(I_{t}\right)$ and underwriting result $\left(U_{t}\right)$ and subtract the taxes $(t r)$. In case of positive earnings we pay for taxis, otherwise we pay nothing. We pay taxes as a portion of the sum of investment result and underwriting result.

$$
E_{t}=U_{t}+I_{t}-\max \left(\operatorname{tr}\left(U_{t}+I_{t}\right), 0\right)
$$

The insurance company can choose two investment options for the assets; high-risk investments or lowrisk investments. The portions of high-risk and low-risk investments in the time period t are denoted respectively by $\alpha_{t-1}$ and $1-\alpha_{t-1}$ and the return of high-risk and low-risk investments are denoted by respectively $r_{1 t}$ and $r_{2 t}$. The rate of return of the company's investment portfolio in $\mathrm{t}, r_{p t}$;

$$
r_{p t}=\alpha_{t-1} r_{1 t}+\left(1-\alpha_{t-1}\right) r_{2 t}
$$

To calculate the investment results we multiply the portfolio return $\left(r_{p t}\right)$ with the funds available for investments $\left(E C_{t-1}+P_{t-1}-E x^{P}{ }_{t-1}\right) \cdot P_{t-1}$ is the premium income and $E x^{P}{ }_{t-1}$ is the upfront costs. 


$$
I_{t}=r_{p t} \underbrace{\left(E C_{t-1}+P_{t-1}-E x_{t-1}^{P}\right)}_{\text {funds available for investments }}
$$

To calculate the premium level we use an underwriting cycle that follows a Markov process. This cycle comprises three possible states. In State 1, there is a strong market and company can have high premium income, in State 2 the company can have medium premium income and in State 3 the market is really soft with low premium income. In the transition probability matrix $p_{s j}$ is used for the transition probabilities from state $\mathrm{s}$ to state $\mathrm{j}$. For example $p_{12}$ denotes the probability of moving from State 1 to State 2 . The transition matrix that includes all possible probabilities;

$$
p_{s j}=\left(\begin{array}{lll}
p_{11} & p_{12} & p_{13} \\
p_{21} & p_{22} & p_{23} \\
p_{31} & p_{32} & p_{33}
\end{array}\right)
$$

The premium income $P_{t-1}$ in period $\mathrm{t}$ depends on the premium rate level $\Pi^{s}$. Depending on underwriting cycle premium rate level $\Pi^{s}$ has three different values for $\mathrm{s}=1,2,3$.

The premium income is also connected to consumer response function, $\mathrm{cr}$. The consumer response function is used for the link between the company's safety level and the written premiums. At the end of the previous term if the equity capital of company is enough, it means company has solvency and is safe for consumers, consumer response function will be equal to 1 . Therefore, for the next term the reliable company expect to obtain all the written premiums. So the premium income;

$$
P_{t-1}=c r_{t-1}^{E C_{t-1}} \Pi_{t-1}^{S} \beta_{t-1} M V(1+i)^{t-1}
$$

In the above equation $M V$ is the market value (all written premiums), $\beta_{t-1}$ is the company's portion of the relevant market in $\mathrm{t}-1$ and $\mathrm{i}$ denotes the average market growth.

We denote expenses with $E_{x}$ and we have two types of expenses; $E x_{t-1}^{p}$ upfront costs and ; $E x_{t}^{C}$ claim settlement costs. Upfront cost depend linearly on the level of written market volume (modeled with the factor $\gamma$ ).

$$
E x_{t-1}^{P}=\gamma \beta_{t-1} M V(1+i)^{t-1}
$$

Claim settlement costs are given as a portion $\delta$ of the claims; $x_{t}^{C}=\delta C_{t}$. We have two different lines of business and so two different types of claims; $C_{C M_{t}}$ compulsory motor insurance claims and $C_{M O D_{t}}$ motor own damage claims. $C_{t}=C_{M O D_{t}}+C_{C M_{t}}$

The underwriting result (premium income minus claims and expense) is thus given by:

$$
U_{t}=P_{t-1}-C_{t}-\left(E x_{t-1}^{P}+E x_{t}^{C}\right)
$$

\section{COPULA METHODOLOGY}

The copula word is used in grammar as "the part of a proposition which connects the subject and predicate" [16].

Sklar states that if $\mathrm{H}$ is a bivariate distribution which margins are $\mathrm{F}(x)$ and $\mathrm{G}(y)$. Then there exists a copula $\mathrm{C}$ such that $\mathrm{H}(\mathrm{x}, \mathrm{y})=\mathrm{C}(\mathrm{F}(\mathrm{x}), \mathrm{G}(\mathrm{y}))$. If $\mathrm{F}$ and $\mathrm{G}$ is continuous then there is a unique $\mathrm{C}$ copula.

Let $F^{-1}(x), G^{-1}(y)$ be inverse distributions, following equations are valid; 


$$
\begin{gathered}
\mathrm{U}=\mathrm{F}(x) \sim U(0,1), \\
\mathrm{V}=\mathrm{G}(y) \sim U(0,1) \\
C(u, v)=P(U \leq u, V \leq v)=P\left(X \leq F^{-1}(u), Y \leq G^{-1}(v)\right) \\
C(u, v)=H\left(F^{-1}(u), G^{-1}(v)\right)
\end{gathered}
$$

Copulas are preferable for who will study dependency because of lots of reasons.

- They are useful to study on nonlinear dependency because they are flexible.

- They allow us to see the potential pitfalls of approaches to dependence that focus only on correlation and shows how to define a number of useful alternative dependence measures.

- Can be more probabilistic or more statistical than the other dependency constructions.

Some similarity transformations and solutions will be constructed from the symmetries.

A large number of copula types are used in the literature. In this section, we present two of the most commonly used families of copula.

\section{Elliptical Copulas}

The normal copula and t copula or Gaussian copula and Student's copula, respectively are two most popular elliptical copulas and they can be easily synthesized numerically [17].

- Gaussian Copula:

The Gaussian copula is derived from the multivariate normal distribution. Let $\Phi$ be the standard normal distribution function and $\Phi_{\rho, n}$ be the n-dimensional standard normal distribution function with correlation matrix $\rho$. Then, the n-dimensional Gaussian copula with correlation $\rho$ is:

$$
C_{\rho, n}^{\text {Gauss }}\left(u_{1}, \ldots, u_{n}\right)=\Phi_{\rho, n}\left(\Phi^{-1}\left(u_{1}\right), \ldots, \Phi^{-1}\left(u_{n}\right)\right)
$$

and density function;

$$
C_{\rho, n}^{\text {Gauss }}\left(u_{1}, \ldots, u_{n}\right)=\frac{\partial C_{\rho, n}^{\text {Gauss }}\left(u_{1}, \ldots, u_{n}\right)}{\partial_{u_{1}} \ldots \partial_{u_{n}}}=\frac{1}{\sqrt{|\rho|}} \exp \left(-\frac{1}{2} y^{t}(u)\left(\rho^{-1}-I_{d}\right) y(u)\right)
$$

In the above equation $y^{t}(u)=\left(\Phi^{-1}\left(u_{1}\right), \ldots, \Phi^{-1}\left(u_{n}\right)\right), I_{d}$ identity matrix, || shows determinant.

- T copula:

The $t$ copula is derived from the multivariate student distribution and exhibits upper and lower tail dependence. We have a n-dimensional student distribution $T_{n, \rho, v}$ with $v$ degree of freedom and $\rho$ corelation matrix;

$$
T_{n, \rho, v}(x)=\frac{1}{\sqrt{|\rho|}} \frac{\Gamma\left(\frac{v+n}{2}\right)}{\Gamma\left(\frac{v}{2}\right)(\pi v)^{n / 2}} \int_{-\infty}^{x_{1}} \ldots \int_{-\infty}^{x_{n}} \frac{d x}{\left(1+\frac{x^{t} \rho^{-1} x}{v}\right)^{\frac{v+n}{2}}}
$$

Therefore the relevant $\mathrm{t}$ copula is: 


$$
C_{n, \rho, v}^{t}\left(u_{1}, \ldots, u_{n}\right)=T_{n, \rho, v}\left(T_{v}^{-1}\left(u_{1}\right), \ldots, T_{v}^{-1}\left(u_{n}\right)\right)
$$

and the density of t-copula is

$$
\begin{gathered}
C_{n, \rho, v}^{t}\left(u_{1}, \ldots, u_{n}\right)=\frac{1}{\sqrt{|\rho|}} \frac{\Gamma\left(\frac{v+n}{2}\right)\left[\Gamma\left(\frac{v}{2}\right)\right]^{n-1}}{\left[\Gamma\left(\frac{v+1}{2}\right)\right]^{n}} \frac{\prod_{k=1}^{n}\left(1+\frac{y_{k}^{2}}{v}\right)^{\frac{v+1}{2}}}{\left(1+\frac{y^{t} \rho^{-1} y}{v}\right)^{\frac{v+n}{2}}} \\
y^{t}=\left(T_{v}^{-1}\left(u_{1}\right), \ldots, T_{v}^{-1}\left(u_{n}\right)\right)
\end{gathered}
$$

\section{$\underline{\text { Archimedian Copulas }}$}

This copula family includes a very large number of copulas enjoying a certain number of interesting properties. They can be used for different dependence structures and lots of them have closed for expressions [17].

The most useful and common used Archimedean copulas:

- Clayton Copula;

$$
\theta \in[-1, \infty] C_{\theta}^{C l}(u, v)=\max \left(\left[u^{-\theta}+v^{-\theta}-1\right]^{-1 / \theta}, 0\right), \theta \in[-1, \infty] \quad \text { with generator } \varphi(t)=\frac{t^{-\theta}-1}{\theta}
$$

When $\theta=-1$, Clayton copula is equal to the lower Fréchet-Hoeffding bound.

- Gumbel Copula;

$C_{\theta}^{G}(u, v)=\exp \left(-\left[(-\ln u)^{\theta}+(-\ln v)^{\theta}\right]^{1 / \theta}\right), \quad \theta \in[1, \infty] \quad$ with generator $\varphi(t)=(-\ln t)^{\theta}$.

- Frank Copula;

$C_{\theta}^{F}(u, v)=-\frac{1}{\theta} \ln \left(1+\frac{\left(e^{-\theta u}-1\right)\left(e^{-\theta v}-1\right)}{e^{-\theta}-1}\right), \quad \theta \in R \quad$ with generator $\varphi(t)=-\ln \frac{e^{-\theta t}-1}{e^{-\theta}-1}$

The Clayton copula has dependence in the lower tail, Gumbel copula exhibits upper tail dependence and the Frank copula exhibits no tail dependence. In this study the Survival Gumbel and Survival Clayton copulas are also considered. Kendall's tau $\tau$ and Spearman's rho $\rho_{s}$ and Pearson's linear correlation coefficient $\rho$ have the following relations:

$$
\begin{aligned}
& \tau=\frac{2}{\pi} \arcsin (\rho) \text { or } \rho=\sin \left(\tau \frac{\pi}{2}\right) \\
& \rho_{s}=\frac{6}{\pi} \arcsin \left(\frac{\rho}{2}\right) \text { or } \rho=2 \sin \left(\rho_{s} \frac{\pi}{6}\right)
\end{aligned}
$$


Therefore we can find Kendall's tau by using the Spearman's rho or Pearson's linear correlation coefficient. Using Kendall's rank correlation coefficient, we can make Archimedean copulas available for the data.There are some expressions of Kendall's $\tau$ for three Archimedean copulas in Table 1.

Table 1. Kendall's Tau correlation of Archimedian Copulas

\begin{tabular}{lcc}
\hline Copula & $\tau$ & range \\
\hline Clayton & $\theta /(\theta+2)$ & $\theta \geq-1$ \\
Gumbel & $1-1 / \theta$ & $\theta \geq 1$ \\
Frank & $1-4 \theta^{-1}\left(1-D_{1}(\theta)\right)$ & $\theta \in R$ \\
\hline
\end{tabular}

Therefore the parameter value $\theta$ can be obtained for any given value of $\tau$.

\section{APPLICATION}

\subsection{Assumptions and Parameters of the Model}

The purpose of this study is to show the importance of the dependency between different lines of business for non-life insurance in DFA. In the application we use the real-word data (Turkey non-life insurance data). In the model there are two lines of business; compulsory motor insurance and motor own damage insurance. We have two main reasons for choosing these lines of business. The first reason is the direct premium divisions for non-life branches. These two lines of business have the biggest portions in direct premium divisions for non-life branches for Turkey 2014 (\%25 CM and \%23 MOD) [18]. The data in the table comes from 2014 Annual Report about Insurance and Private Pension Activities that Republic of Turkey Prime Ministry Under-secretariat of Treasury published. Similar to premiums, these two lines of business have the biggest portions of paid loss in nonlife insurance. The second reason is the high correlation between CM and MOD. We examine the annual reports about insurance and private pension activities that Republic of Turkey Prime Ministry Under secretariat of Treasury published between 2002 and 2014. The paid loss data for CM and MOD have been deflated to 2014. The Kendall's Tau correlation coefficient between CM and MOD is 0,2051. This correlation was higher in the previous years and can have important effects in DFA.

The dependencies between CM and MOD can be integrated in DFA by generating correlated random numbers. We use copulas to model dependencies and Kendall's tau correlation coefficient. We use different copulas such as; Gaussian copula, T copula, and Gumbel, Clayton and Frank copulas which are Archimedean copulas and survival Gumbel and survival Clayton copulas to model correlations. We prefer these copulas because of their ease of use like parameterized easily and extensively used in the literature.

The simulation study is conducted for a five-year period starting in 2014. The initial market value is 10.043.613.000TL (the total written premium for CM and MOD in the beginning of 2014 in Turkey). We examine Turkey CM and MOD insurance market growth for last ten years "2005-2014". The growth is not linear so we use the average of ten years market growth (-0.0527425). Company's underwriting market share $\beta_{t-1}$ is assumed as 0,15 (this value is rather close to the market share of the biggest nonlife insurance company of Turkey in 2014) and the equity capital is 413.809.207 TL. Investment returns are normally distributed [15]. For the best estimate of the mean and the standard deviations of returns, the last 5 years high risk and low risk investments reel returns of Turkey are observed. CM and MOD claims are log-normally distributed $[19,20]$. We assume the company is safe and has enough equity capital so the consumer response function is " 1 ". For assuming the portion invested in high-risk investments we study on how the assets of non-life insurance companies in Turkey are divided in high risk investments and low risk investments from 2010 to 2014. Then the initial value of portion invested in low-risk investments is selected as \%75 in simulation.To denote the 
probabilities of switching from one state to another in the transition matrix, the previous years' markets should be determined as State 1, State 2 and State 3 and then the transitions should be observed. This requires a long term study and such a study for Turkey is not available so we use the transition matrix which is given in Eling, Parnitzke, and Schmeiser's paper [6]

$$
p_{s j}=\left(\begin{array}{lll}
0.1 & 0.5 & 0.4 \\
0.2 & 0.6 & 0.2 \\
0.3 & 0.5 & 0.2
\end{array}\right)
$$

We have 3 different premium levels for 3 states. For state 1 (weak competition in the market) companies get higher premiums than they expect, so premium rate level $\Pi^{1}=1,05$. For state 2 (normal competition) premium rate level is equal $1, \Pi^{2}=1$. For the state 3 (strong competition) insurance companies cannot get the whole premium that they expect so $\Pi^{3}=0,95$. We assume the initial state as State 2 . We can find the model parameters in Table 2.

Table 2. Model parameters

\begin{tabular}{|c|c|c|c|}
\hline Symbol & Initial value (t=0) & Symbol & Initial value (t=0) \\
\hline$T$ & 5 & $c r_{t-1}^{E C_{t-1}}$ & 1 \\
\hline$E C_{t}$ & $413.809 .207 \mathrm{TL}$ & $\gamma$ & 0,05 \\
\hline$t r$ & 0,25 & $E\left(C_{M O D}\right)$ & $476.103 .574 \mathrm{TL}$ \\
\hline$\alpha_{t-1}$ & 0,25 & $\sigma\left(C_{M O D}\right)$ & $104.368 .760 \mathrm{TL}$ \\
\hline$E\left(r_{1 t}\right)$ & 0,072 & $\delta$ & 0,05 \\
\hline$\sigma\left(r_{1 t}\right)$ & 0,3223 & $E\left(C_{C M}\right)$ & $299.950 .096 \mathrm{TL}$ \\
\hline$E\left(r_{2 t}\right)$ & 0,076 & $\sigma\left(C_{C M}\right)$ & $137.189 .024 \mathrm{TL}$ \\
\hline$\sigma\left(r_{2 t}\right)$ & 0,065 & $\tau$ & 0,2051 \\
\hline$r_{f}$ & 0,03 & $\Pi^{s}$ & 1,05 \\
\hline$M V$ & $10.043 .613 .000 \mathrm{TL}$ & $\Pi^{1}$ & 1 \\
\hline$i$ & $-0,052$ & $\Pi^{2}$ & 1 \\
\hline$\beta_{t-1}$ & 0,15 & $\Pi^{3}$ & \\
\hline
\end{tabular}

\subsection{Results of the Simulation}

The financial ratios which are used for the measurement of performance, risk and return are shown in Table 3 [6].

Table 3. Financial ratios

\begin{tabular}{ccc}
\hline & Symbol & Measure \\
\hline Return & $E(G)$ & expected gain per annum \\
Risk & $\sigma(G)$ & standart deviation of gain per annum \\
& $R P$ & ruin probability \\
& $E P D$ & expected policyholder deficit \\
Performance & $S R_{\sigma}$ & sharpe ratio \\
& $S R_{R P}$ & modified sharpe ratio (RP) \\
& $S R_{E P D}$ & modified sharpe ratio (EPD) \\
\hline
\end{tabular}

For the measure of the return expected gain per annum is used and the formulas;

$$
E(G)=\frac{E\left(E C_{T}\right)-E C_{0}}{T}
$$


For the measure of the risk standard deviation of gain per annum $\sigma(G)$, ruin probability $R P$ and expected policyholder deficit $E P D$ are used and their formulas respectively; $\sigma(G)=\sigma\left(E C_{T}\right) / T$ $R P=\operatorname{Pr}(\hat{\tau} \leq T) \hat{\tau}=\inf \left\{t>0 ; E C_{t}<0\right\} \quad t=1,2, \ldots, T$ describes the first occurrence of ruin and $E P D=\sum_{t=1}^{T} E\left[\max \left(-E C_{T}, 0\right)\right]\left(1+r_{f}\right)^{-t} \quad r_{f}$ stands for the risk-free rate of return.

For the measure of the performance we use Sharpe ratios. The Sharpe ratio $S R_{\sigma}$ is a widely known performance measure and measures the relationship between the risk premium and the standard deviation of returns. The formula for the sharpe ratio is $S R_{\sigma}=\frac{E\left(E C_{T}\right)-E C_{0} \cdot\left(1+r_{f}\right)^{T}}{\sigma\left(E C_{T}\right)}$ and modified sharpe ratio (RP) and modified sharpe ratio (EPD) are defined as respectively; $S R_{R P}=\frac{E\left(E C_{T}\right)-E C_{0} \cdot\left(1+r_{f}\right)^{T}}{R P}, S R_{E P D}=\frac{E\left(E C_{T}\right)-E C_{0} \cdot\left(1+r_{f}\right)^{T}}{E P D}$.

The results of the simulation for the financial ratios are shown in Table 4. Table shows the simulation results which we get from MATLAB with 100.000 iterations. The results are shown for 7 different copulas and also for the case without correlation. We evaluate the results in the sense of financial ratios. Firstly we consider the case without correlation. We find an expected gain of 494.300 .000 TL per annum with a standard deviation $139.300 .000 \mathrm{TL}$. The ruin probability is 0,0060 and the expected policyholder deficit is $1.802 .600 \mathrm{TL}$. Later we compare the case with correlation and without correlation. In the sense of expected gain per annum as a measure of return there is not a big difference between these cases. However, we find considerable differences in risk and performance. Standard deviation of gain per annum $\sigma(G)$, ruin probability $R P$ and expected policyholder deficit $E P D$ are much higher than in the case without correlation and the measurements of performance are much lower than in the case without correlation. . In the case with correlation; measurements of risk are much higher, on the contrary measurements of performance are much lower than in the case without correlation.

In the case that exhibit upper tail dependence, the ruin probability is higher than in the case that exhibit lower tail dependence. This finding shows while integrating the dependency between lines of business in DFA, tail dependence of data should be considered for selecting of ideal copula.

Table 4. The results of the simulation

\begin{tabular}{|c|c|c|c|c|c|c|c|c|}
\hline $\begin{array}{l}\text { tail } \\
\text { dependence }\end{array}$ & $\begin{array}{l}\text { dependence } \\
\text { structure }\end{array}$ & $\begin{array}{c}E(G) \\
\text { billion } \\
T L \\
\end{array}$ & $\begin{array}{c}\sigma(G) \\
\text { billion } \\
T L \\
\end{array}$ & $R P$ & \begin{tabular}{c|}
$E P D$ \\
million \\
$T L$ \\
\end{tabular} & $S R_{\sigma}$ & $\begin{array}{l}S R_{R P} \\
\text { billion }\end{array}$ & $\begin{array}{l}S R_{E P D} \\
\text { thous and }\end{array}$ \\
\hline None & No Correlation & 0,4943 & 0,1393 & 0,0060 & 1,8026 & 3,4520 & 400,26 & 1,3345 \\
\hline None & Gaussian & 0,4938 & 0,1496 & 0,0101 & 3,1323 & 3,2123 & 237,70 & 0,7672 \\
\hline \multirow{5}{*}{$\begin{array}{l}\text { Upper } \\
\text { and } \\
\text { Lower }\end{array}$} & \multirow{5}{*}{$\mathrm{t}$} & 0,4930 & 0,1508 & 0,0163 & 5,7770 & 3,1813 & 147,29 & 0,4152 \\
\hline & & 0,4927 & 0,1510 & 0,0141 & 4,6876 & 3,1754 & 170,19 & 0,5115 \\
\hline & & 0,4936 & 0,1504 & 0,0140 & 4,9000 & 3,1937 & 171,10 & 0,4902 \\
\hline & & 0,4946 & 0,1494 & 0,0123 & 4,1634 & 3,2212 & 196,05 & 0,5780 \\
\hline & & 0,4937 & 0,1494 & 0,0120 & 4,0846 & 3,2149 & 200,08 & 0,5882 \\
\hline Upper & Gumbel & 0,4930 & 0,1525 & 0,0168 & 6,432 & 3,1455 & 142,89 & 0,3729 \\
\hline Lower & Survival Gumbel & 0,4924 & 0,1590 & 0,0158 & 4,7558 & 3,0126 & 152,14 & 0,5038 \\
\hline Lower & Clayton & 0,4946 & 0,1473 & 0,0077 & 2,4467 & 3,2673 & 311,85 & 0,9830 \\
\hline Upper & Survival Clayton & 0,4924 & 0,1536 & 0,0181 & 5,8666 & 3,1190 & 132,53 & 0,4084 \\
\hline None & Frank & 0,4947 & 0,1486 & 0,0089 & 2,7624 & 3,2374 & 270,39 & 0,8711 \\
\hline
\end{tabular}


Focusing on tail dependence, Figure 1 compares three total claims data sets which include 1 million $\mathrm{CM}$ insurance and MOD insurance claims that are simulated using the Gumbel (upper tail), the Clayton (lower tail), and the Frank (none) copulas.

Figure 1 and Figure 2 show us the total claims which are simulated with the Gumbel copula (upper tail) are higher than the others and have the higher ruin probability. CM insurance claims' frequencies and MOD insurance claims data have the upper tail dependency. We believe that, if we want to simulate an upper tail dependent data set but use a lower tail dependent copula the results will not reflect the truth (lower or higher EPD, RP,etc), vice versa. Consequently selecting the right copula is require and significant.

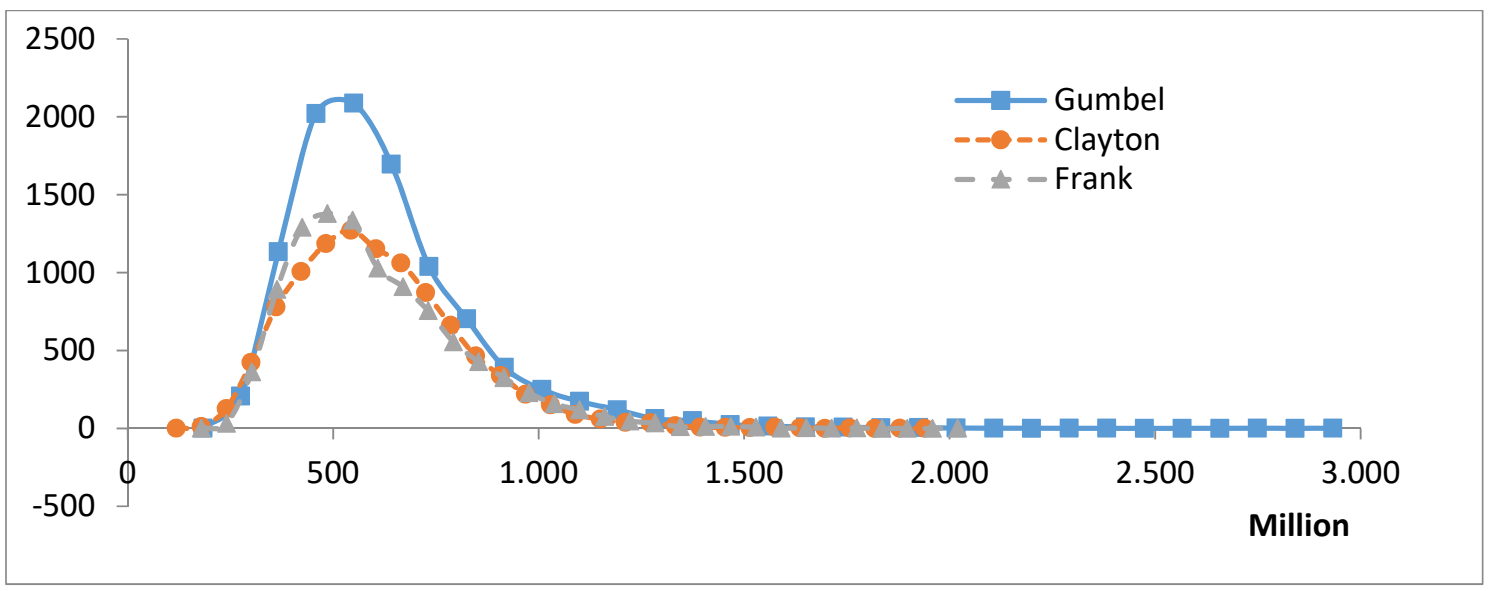

Figure 1. Total claims which are simulated with Gumbel, Frank and Clayton Copulas

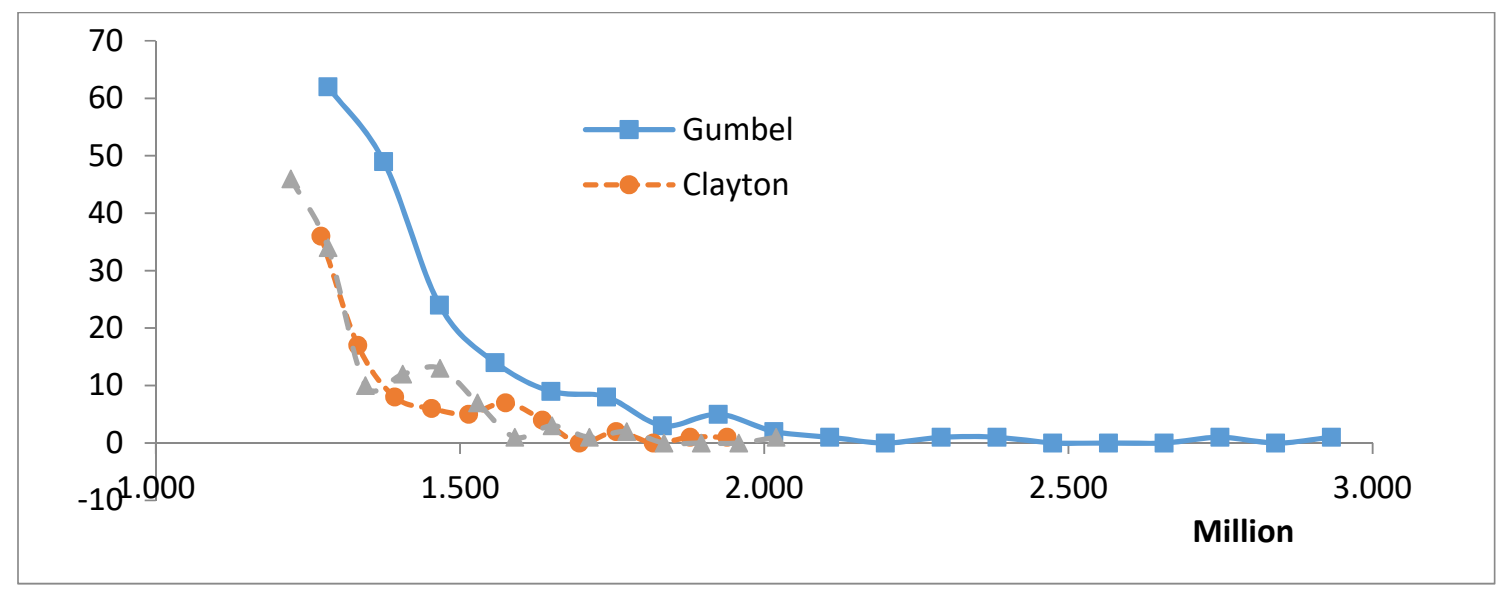

Figure 2. Tails of three total claims distributions

\section{CONCLUSION}

In this study we considered real World data from Turkey by using DFA with copulas for modelling dependency. The integration of the correlation between CM and MOD in DFA for a non-life insurance company has important effects on the risk and performance. This result is also relevant for rating agencies and regulators because we find large differences in risk assessment for different risk measures between the case with correlation and the case without correlation.

As mentioned in the DFA section there is not a unique methodology for DFA and insurance companies can construct different models that include necessary components for themselves. In this 
way they can consider the dependency between all lines of business which are relevent for them. In this paper we just consider the correlation between the MOD insurance and CM insurance and integrate into DFA. The reason of this choice is the importance of these two lines of business in a nonlife insurance company. They have the biggest share in premiums and claims. For future studies we can include all the lines of business and the correlation between them in DFA.

\section{REFERENCES}

[1] Casualty Actuarial Society. Dynamic Risk Modeling Handbook. prepared by the CAS Dynamic Risk Modeling Working Party, 2006.

[2] Lowe SP, Stanard JN. An Integrated Dynamic Financial Analysis and Decision Support System for a Property Catastrophe Reinsurer. Astin Bulletin 1997; 27, 339-371.

[3] Kaufmann R, Gadmer A, Klett R. Introduction to Dynamic Financial Analysis. Astin Bulletin 2001; 31(1), 213-249.

[4] Blum P, Dacarogna M, Emrechts P, Neghaiwi T, Niggli H. Using DFA for Modeling the Impact of Foreign Exchange Risks on Reinsurance Decisions. Casualty Actuarial Society Forum 2001.

[5] D'Arcy SP, Gorvett RW. The Use of Dynamic Financial Analysis to Determine Whether an Optimal Growth Rate Exists for a Property-Liability Insurer. Journal of Risk and Reinsurance 2004; 71, 583-615.

[6] M. Eling, T. Parnitzke, H. Schmeiser. Management Strategies and Dynamic Financial Analysis. Variance 2008; 2(1): 52-70.

[7] Sklar A. Fonctions de répartition à n dimensions et leurs marges. Publ. Inst. Statist. Univ., Paris 8: 229-231, 1959.

[8] Wang S. Aggregation of Correlated Risk Portfolios: Models and Algorithms. Proceedings of the Casualty Actuarial Society; 1998; 85(163): 848-939.

[9] Klugman SA, Parsa R. Fitting Bivariate Loss Distributions with Copulas. Insurance: Mathematics and Economics 1999; 24(1): 139-148.

[10] Zeevi A, Mashal R. Beyond Correlation: Extreme Co-Movements Between Financial Assets. Working Papers Series 2002.

[11] Malevergne Y, Sornette D. Testing the Gaussian Copula Hypothesis for Financial Assets Dependences. Quantitative Finance 2003; 3(4): 231-250.

[12] Dias A. Copula Inference for Finance and Insurance, Doctoral Thesis ETH No. 15283, Zurich, 2004

[13] Kole E, Koedijk K, Verbeek M. Selecting Copulas for Risk Management, Journal of Banking \& Finance 2207; 31(8): 2405-2423.

[14] Burkett JC, McIntyre T, Sonlin SM. DFA Insurance company case study part I: Reinsurance and asset allocation. Casualty Actuarial Society Forum, Summer 2001; Arlington, VA: Casualty Actuarial Society. 
Karagül and Büyükyazıcı / Anadolu Univ. J. of Sci. and Technology A-Appl. Sci. and Eng. 18 (5) - 2017

[15] Eling M, Toplek D. Modeling and management of nonlinear dependencies -copulas in dynamic financial analysis. The Journal of Risk and Insurance 2009; Vol. 76, No. 3, 651-681.

[16] Simpson J, Weiner E. The Oxford English Dictionary, second edition: Oxford University Press, United Kingdom, 1989.

[17] Malevergne Y, Sornette D. Extreme Financial Risks: From Dependence to Risk Management: Springer, 2006.

[18] Annual report about insurance and private pension activities. Republic of Turkey Prime Ministry Under secretariat of Treasury insurance Supervision Board, 2014

[19] Adeleke IA. Modeling claim sizes in personal line non-life insurance. International Business and Economic Research Journal Februray 2011; volume 10 number 2.

[20] Achieng OM. Actuarial modeling for insurance claim severity in motor comprehensive policy using industrial statistical distributions. International Congress of Actuaries; 7-12 March 2010; Cape Town. 